\title{
THE POTENTIAL IMPACTS OF GOLD NANOPARTICLES ON THE MUCOUS MEMBRANE OF THE ALBINO RATS' TONGUES
}

\author{
Mai Osman El-Halwagy ${ }^{1}$, Enas Mahmoud Hegazy ${ }^{2}$, Mervat Mohamed Youssef ${ }^{3}$, Laila Sadek Ghali ${ }^{4}$
}

DOI: $10.21608 / d s u .2020 .16899 .1011$

\section{KEYWORDS}

Gold nanoparticles,

Biodistribution,

Histological examination,

Reactive oxygen species,

Tongue papillae,

Toxicity.

- E-mail address:

maielhalwagy1412@gmail.com

1. Demonstrator, Oral Biology Department, Faculty of Dentistry, Sinai University.

2. Associate Professor, Oral Biology Department, Faculty of Dentistry, Suez Canal University.

3. Associate Professor, Head of Oral Biology Department, Faculty of Dentistry, Suez Canal University.

4. Professor, Oral Biology Department, Faculty of Oral and Dental Medicine, Cairo University.

\begin{abstract}
Introduction: With the growing interest in the applications of gold nanoparticles (AuNPs) in biotechnology and their physiological effects, possible toxicity of gold nanoparticles is becoming an increasingly important issue. It was shown that the toxicity is both dose- and size-dependent, and the AuNPs of higher concentration would cause more cytotoxicity. Aim: Aim of this work was to study the toxic effect of intraperitoneal administration of gold nanoparticles -if any- on the mucous membrane of the tongues of albino rats and the possibility of one-month recovery period. Material and Methods: Forty-six male albino rats were used in the present investigation. They were divided into the following groups: Group (1) (16 rats) served as controls, they received the solvent of AuNPs intraperitoneally daily for 21 days. Group (2) (15 rats) received $10 \mathrm{mg} / \mathrm{kg}$ body weight of AuNP solution intraperitoneally daily for 21 days. Group (3) (15 rats) were treated the same way as Group 2 for 21 days and then left for one-month as a recovery period. Results: Examination of the tongue of the rats which were exposed to gold nanoparticles solution revealed atrophic and degenerative changes of both the dorsal and ventral surfaces of the tongue as well as the lingual salivary glands. The examined tongues of the rats which were allowed a recovery period showed improvement in the histological picture. Conclusion: Exposure to over dose of AuNPs causes atrophic and degenerative changes. A recovery period of one-month can lead to regeneration and improvement in the histological picture.
\end{abstract}

\section{INTRODUCTION}

Nanotechnology is emerging as an interdisciplinary field that is undergoing rapid development and has brought about enormous changes in medicine and dentistry ${ }^{1}$. It involves the understanding, design, engineering and fabrication of materials at the atomic and molecular level ${ }^{2}$.

Gold nanoparticles (AuNPs) are some of the most extensively studied nanomaterials. They are emerging materials that exhibit characteristics distinct from those of traditional materials and that have promising potential for application in the fields of chemistry, physics, biology, and medicine ${ }^{3}$.

Properties of gold nanoparticles such as shape, size, surface chemistry, targeting ligand, elasticity, and composition largely influence 
their toxicity. This, in combination with the complexity and the heterogeneity that exists amongst human cells and tissues, makes it challenging to comprehensively probe the effect and response of the biological system to the administration of gold nanoparticles ${ }^{4}$.

Surface charge has been reported to influence toxicity of gold nanoparticles, wherein positively charged particles were found to be more toxic than negative or neutral particles ${ }^{5}$. On the other hand, other groups found no toxicity induced by positively charged gold nanoparticles ${ }^{6}$ and no toxicity of negatively charged particles ${ }^{7}$. This discrepancy arises due to the unique physiochemical nature of nanoparticles, and no single standardized assay is currently available that could universally be applied to test the toxicity effect of all nanoparticles.

Increased cytotoxicity of smaller gold nanoparticles when tested on a human hepatic cell line was reported as compared to that of the larger particles. ${ }^{8}$ However, it was reported that regardless of the size of the nanoparticles, the observed cytotoxicity was due to dose-dependency ${ }^{9}$.

A similar accumulation of gold nanoparticles in the liver was reported while testing the effect of nanoparticle size on biodistribution. It was observed that gold nanoparticles of all sizes mainly accumulated in organs like liver, lung, and spleen ${ }^{10}$.

The metallic nature of the AuNPs and the presence of the transition metals core encourage the production of reactive oxygen species (ROS) leading to oxidative stress. ${ }^{11}$ Furthermore, once these nanoparticles enter a biological system, they can strongly associate with a diverse range of molecules present in the extra- and intracellular environment ${ }^{12}$.

Recent studies have focused on the potential of nanomaterials to cause oxidative stress ${ }^{13}$. This occurs when cellular defenses against reactive oxygen species (ROS) are exceeded and redox homeostasis is lost $^{14}$. Thus, Gold nanoparticles have been related to imbalances in oxidative status ${ }^{15,16}$.

The immunohistochemical detection of the proliferative cell nuclear antigen (PCNA) indicates the rate of cell activity of the epithelium of rats. So it can be used as a monitor to determine the impacts of AuNPs on epithelial cells.

Up to our knowledge, the effects of AuNPs on the oral tissues and salivary glands have not been investigated yet.

\section{MATERIAL AND METHODS}

This study was approved by the ethical committee of Faculty of Dentistry Suez Canal University (n.2018/91).

Forty-six adult male albino rats with an average 150-180gram body weight were used in the present investigation. They were divided into the following groups:

Group 1: consisted of 16 rats served as controls, they received the solvent of AuNP $(0.5 \mathrm{ml}$ deionized water) intraperitoneally daily for 21 days and were subdivided as follows:

Subgroup 1.1: half the animals of the control group, was euthanized after 21 days.

Subgroup 1.2: the other half was left untreated for one more month, then euthanized.

Group 2: consisted of 15 rats. They received $10 \mathrm{mg} / \mathrm{kg}$ body weight of AuNP solution ${ }^{17}$ dissolved in $0.5 \mathrm{ml}$ deionized water (particle sizes around $30 \mathrm{~nm})^{18}$ intraperitoneally daily for 21 days.

Group 3: consisted of 15 rats. They were treated the same way as group 2 animals for 21 days and then left for one-month as recovery period. 


\section{Preparation and characterization of the gold nanoparticles:}

Rapid green method was used for preparation and characterization of gold nanoparticles. Pomegranate fruits were collected from the local market. Chloroauric acid (> 99.9\%) was obtained from International Company for Scientific and Medical Supply. All glassware and pome fruit were properly washed with de-ionized water and were dried in oven. Fruit peel extract (FPE) of pome were used as a reducing agent for the development of gold nanoparticles.

Properly washed $50 \mathrm{~g}$ of fresh peels of the fruit were added in $250 \mathrm{ml}$ ultra-pure water in $500 \mathrm{ml}$ Erlenmeyer flask and boiled for 10-15 minutes. Whatman filter paper (No. 40) was used for filtration of boiled material to prepare an aqueous fruit peel extract, which was used as such for metal nanoparticle synthesis.

Aqueous solution $(1 \mathrm{mM})$ of chloroauric acid solution was prepared and $50 \mathrm{ml}$ of the metal $(\mathrm{Au})$ ion solution was reduced using $1.8 \mathrm{ml}$ of FPE at room temperature for 5 minutes. Below this FPE quantity, the solution takes more than 10 minutes to get a significant surface plasmon resonance (SPR) for the metal nanoparticle. As a result, pink color solution indicating the formation of gold nanoparticles was achieved after the addition of fruit peel extract (FPE).

Spectral analysis for the development of nanoparticles at different reaction conditions was observed by X-Ray diffractometer (XRD). Transmission electron microscope (TEM) JEM-1200EX, JEOL 1010 was used for the size and shape analysis of developed nanoparticles.

At the end of the experiment, the animals of the different groups were euthanized by cervical dislocation; their tongues were dissected out, fixed in $10 \%$ neutral buffered formalin, processed and embedded in paraffin. Six microns' thick sections were cut to be stained.

\section{Preparation of the specimen for examination by light microscopy:}

Specimen from all rats' tongue were fixed in $10 \%$ formol saline. Paraffin blocks were prepared and $5 \mu$ sections were stained using Haematoxylin and Eosin (H\&E) stain.

\section{Preparation of Specimen for PCNA immunohis- tochemical detection:}

Sections were preincubated in absolute methanol to block any endogenous peroxidase activity without affecting the immunoreactivity of the antigen. Sections then were rinsed gently with phosphate buffer solution then were incubated for 10 minutes with non-immune serum (Reagent 1A). Two drops (equivalent to $100 \mu 1$ ) of primary antibody were applied to each section and left for 30-60 minutes. Sections were rinsed well with PBS 3 times 2 minutes each. Excess buffer was removed and slides were wiped.

Two drops of biotinylated second antibody (Reagent 1B) containing antimouse antibody were applied to each section and incubated for $10 \mathrm{~min}$ utes. Then sections were rinsed in 3 PBS with different concentrations 2 minutes each.

Primary Antibody; Name: PCNA antibody, Clone: PC-10, Mouse anti-Rat, Supplier: Santa Cruz Biotechnology, Catalog Number: sc-56, Dilution: 1:2000 using IHC-TekTM Antibody Diluent (Cat\# IW-1000 or IW-1001) to reduce background and unspecific staining and serum blocking step is NOT needed and Incubation Time/Temp: $60 \mathrm{~min} / \mathrm{room}$ temperature. 
Antigen Retrieval; Device: IHC-TekTM Epitope Retrieval Steamer Set (Cat\# IW-1102), Buffer/ pH value: IHC-TekTM Epitope Retrieval Solution (Cat\# IW-1100), Heat/Cool Temperature: 95-100 ${ }^{\circ} \mathrm{C} /$ room temperature and Heat/Cool Time: 20 minutes/20 minutes.

Then sections were counter stained with hematoxylin. Slides were examined under the light microscope and the PCNA labeling index the number of PCNA positive cells divided by the total cell number in the basal cell layer\} was estimated and treated statistically. Any nuclear staining regardless the intensity was considered immunopositive.

\section{Preparation of the specimen for examination by scanning electron microscopy:}

Representative tongue specimens from the rats of all groups were fixed in $2.5 \%$ glutraldhyde in $0.1 \mathrm{M}$ phosphate buffer (PH 7.4) for 4 hours. Then, the samples were washed with phosphate buffer and post fixed in $1 \%$ osmium tetroxide for 90 minutes then the samples were washed again with phosphate buffer and dehydrated through series of ascending concentrations of ethanol to $100 \%$ amylacetate. ${ }^{19}$

After that, samples were coated with gold under vaccum with sputter coater. After gold coating, tongue samples were examined and photographed with JEOL, JSM-53009 scanning electron microscope in EM unit, Central Laboratories Sector, The Egyptian Mineral Resources Authority, Cairo.

\section{RESULTS}

\section{Histological Results: (Haematoxylin and Eo- sin stain)}

The histological examination of hematoxylin and eosin stained sections of the mucous membrane of the tongue of the control rats showed the nor- mal histological features of surface epithelium and underlying lamina propria both in sub-groups 1.1 and 1.2.

The filliform papillae (fig.1A) appeared sharp conical covered with stratified squamous epithelium with thin regular keratin layer.

The fungiform papillae (fig.1B) were seen in between filliform ones with broader surface and wide vascular connective tissue core and most often at the tip and lateral borders of the body of the tongue.

The circumvallate papilla (fig.1C) was single and located region near the $\mathrm{V}$ shaped sulcus terminalis. It was surrounded with a circular furrow. A lot of taste buds were found in the side walls of the papilla and furrows.

Examination of the tongues of rats which were exposed to AuNPs revealed atrophic and degenerative changes that involved the surface epithelium and lamina propria of both the dorsal and ventral surfaces of the tongue as well as the lingual salivary glands.

The filliform papillae (fig.2A) lost the normal appearance. They were markedly atrophic, their number and height were apparently much decreased when compared with those of the control animals. Most of them appeared stunted with total or partial loss of their characteristic conical shape and evident hyperkeratosis. Their epithelial covering showed marked atrophy and the lamina propria showed signs of degeneration.

The fungiform and circumvallate papillae showed signs of atrophy in their epithelium and lost their normal configuration (fig.2B, 2C). Taste buds appeared shrunken, partially lost their cells or completely absent. 


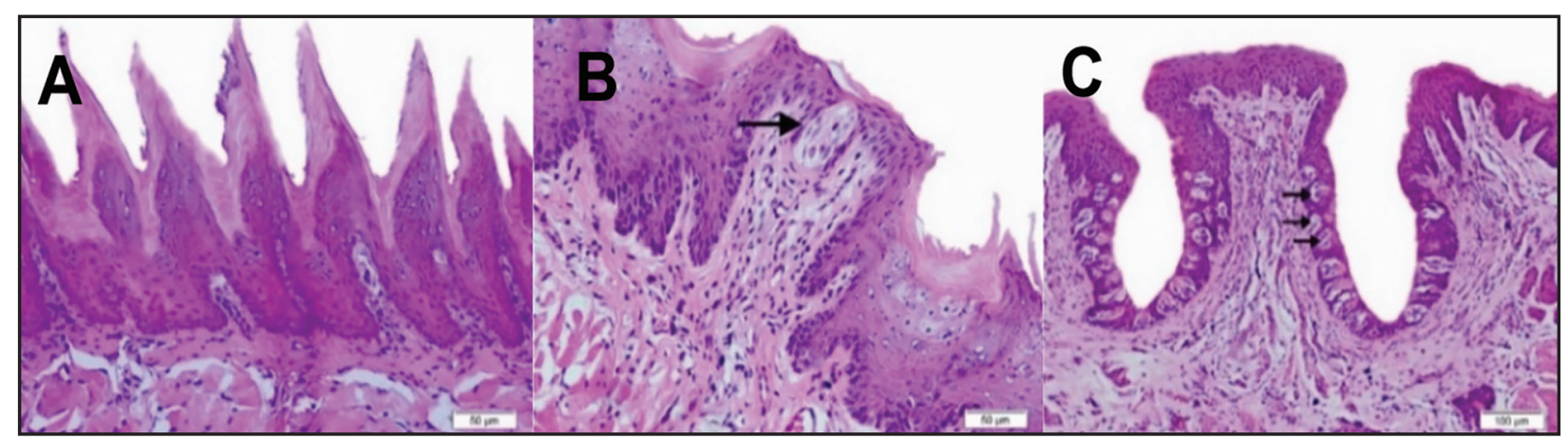

Fig. (1) Photomicrographs of the dorsal surface of the control tongue showing: A-Sharp conical projections of filiform papillae with thin smooth keratinized epithelial covering and lamina propria. Skeletal muscle fibers running in different directions are seen underneath the papillae. B-A fungiform papilla with normal barrel like intraepithelial taste bud (arrow). C-A circumvallate papilla with a lot of taste buds at its side walls (arrows) (H\&E, orig. mag. A-200 , B-200, C-100)

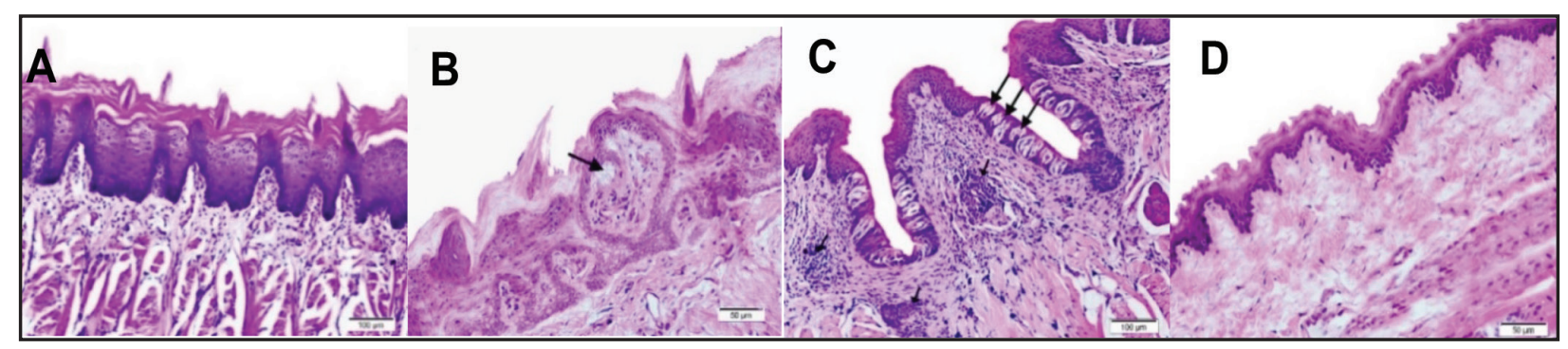

Fig. (2)A photomicrograph of the dorsal surface of the tongue of group 2 rats showing: A-Atrophy and apparent decrease in the height and number of filiform papillae. B-Fungiform papilla (among atrophic filiform papillae) with degenerated taste bud (arrow). C-Circumvallate papilla showing atrophy of the taste buds with degenerating cells (large arrows) and collection of inflammatory cells in the lamina propria (small arrows). D-The ventral surface of the tongue of group 2 rats showing atrophy of the surface epithelium and dissociation of collagen fibers of the lamina propria (H\&E, orig. mag. A-100, B-200, C-100, D-200).

The ventral surface of the tongue of rats exposed to AuNPs showed marked atrophic and degenerative changes in its mucous membrane presented as reduction of the thickness of the surface epithelium, dissociation of the collagen fibers of the lamina propria with dilatation of blood vessels (fig.2D).

The examined tongues of the rats which were allowed a recovery period for one-month after 21 days of intraperitoneal treatment with AuNPs showed improvement in the histological picture of the surface epithelium and lamina propria of the dorsal and ventral surfaces of their tongues as well as their lingual salivary glands.
There was regain in the number and height of the filliform papillae in comparison with group 2 rats (fig.3A). The fungiform and circumvallate papillae appeared more or less normal without signs of shrinkage or degeneration. Their taste buds got regenerated and appeared more or less normal (fig.3B).

The surface epithelium of the ventral surface of the tongues had normal thickness of surface epithelium, normal pattern of epithelial ridges with normal density of collagen fibers of its lamina propria (fig.3C). 


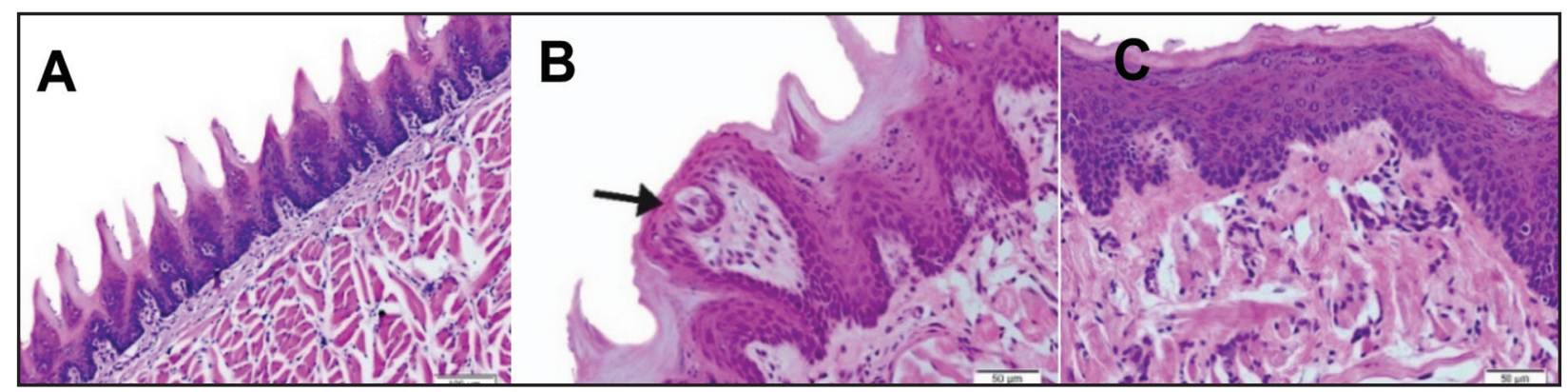

Fig. (3) Photomicrographs of the dorsal surface of the control tongue showing: A-Sharp conical projections of filiform papillae with thin smooth keratinized epithelial covering and lamina propria. Skeletal muscle fibers running in different directions are seen underneath the papillae. B-A fungiform papilla with normal barrel like intraepithelial taste bud (arrow). C-A circumvallate papilla with a lot of taste buds at its side walls (arrows) (H\&E, orig. mag. A-200 , B-200, C-100)

\section{Immunohistochemical results: (Proliferating Cell Nuclear Antigen (PCNA)}

The histological sections of tongues of the controls revealed moderately to strongly positive PCNA staining reaction mainly at the basal and parabasal cells of the surface epithelium indicating normal proliferation of the cells of the dorsal and ventral surfaces of the tongue. All the basal cells were positively stained (fig.4A).

The sections of the tongues of rats exposed to AuNPs showed low expression of PCNA in the basal layer of the epithelium of the dorsal and ventral surfaces of the tongue ranging from negative to weakly positive staining reaction which indicated a decrease in proliferation of basal and parabasal cell layers denoting marked decrease in the rate of turnover and cell renewal. Most of the basal cells were negatively stained (fig.4B,4C).

The sections of the tongues of rats allowed for recovery showed moderately to strongly positive PCNA expression in the basal and parabasal cells of the dorsal and ventral surfaces of the tongue (fig.4D).

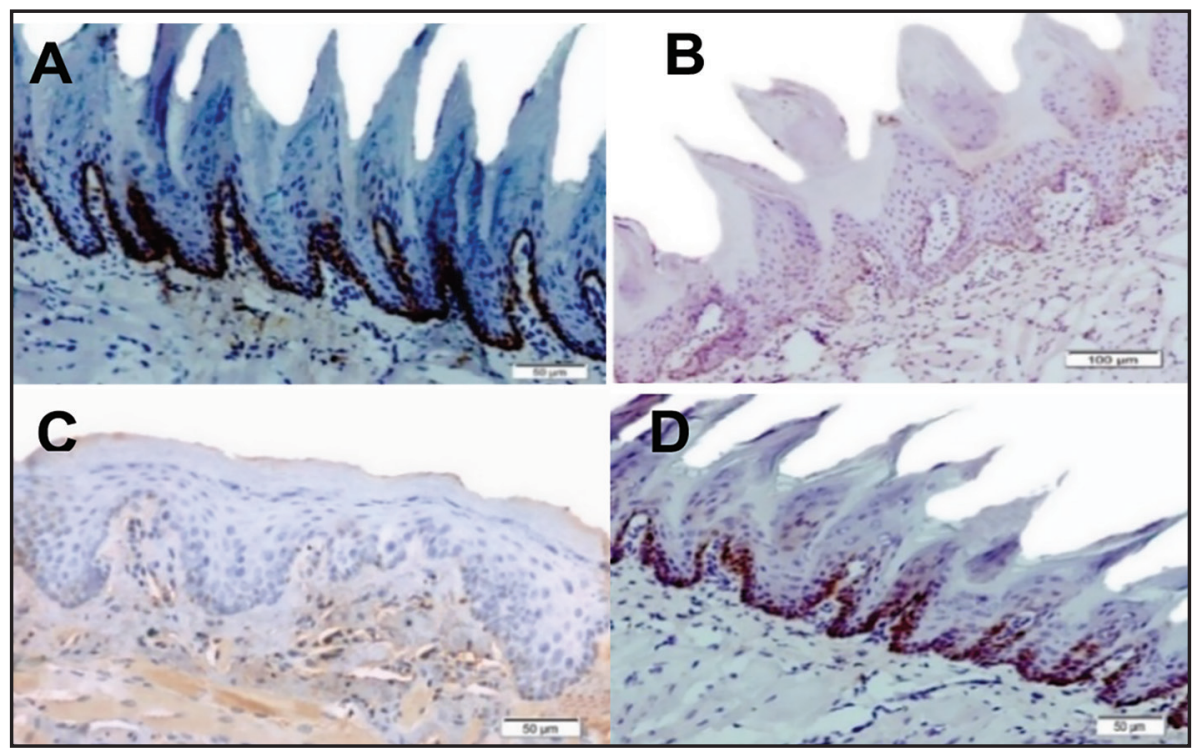

Fig. (4) A photomicrograph of the tongue showing: A-The dorsal surface of the tongue of group 1 rats showing strongly positive PCNA staining of the basal cells of the epithelium of filiform papillae. B-The tongue of group 2 rats showing the dorsal surface with negative to weakly positive staining reaction of the basal cells to PCNA. C-The ventral surface of the tongue of group 2 rats showing negative to weakly positive staining reaction of the basal cells to PCNA. Most of the basal cells are negatively stained. D-The dorsal surface of the tongue of group 3 rats showing moderately to strongly positive PCNA staining of the basal. Almost all the basal cells are positively stained (orig.mag. A-200, B-100, C-200, D-200). 


\section{Scanning Electron Microscopic results:}

Examination of the dorsal surface of the control rats' tongues showed numerous sharp conical projections of Filliform papillae with uniform keratinized tips arranged in parallel regular rows depicting constant antero-posterior direction towards the tongue root.

Scattered fungiform papillae with broad apices were seen among numerous filliform ones, they were dome-shaped or mushroom shaped and wider in diameter than the filliform ones. Thin epithelial smooth cells were depicted around centrally located well defined regular gustatory pore surrounded by shallow indentation (fig.5A).

Examination of the dorsal surface of rats' tongues which were exposed to AuNPs revealed numerous filliform papillae with evidently disturbed orientation and inclination. They showed an apparent decrease in number and change in distribution. The degeneration of filiform papillae gave them appearance of stunted accessory processes around the main protrusion. They became thinner having more slender shape than a conical one with abnormal extreme bending or sometimes looping. Others were covered by constricted keratin. Blunt eroded tips of some filliform papillae were also seen (fig.5B).

Fungiform papillae with wrinkled heavily keratinized epithelial covering were depicted (fig.5C). They were smaller in size, shrunken, atrophied and degenerated. The taste pore was frequently invisible in the central region at the top of each fungiform papilla. Sometimes the gustatory pore appears depressed, irregular, ill-defined, or obliterated.

The examined tongues of the rats which were allowed a recovery period for one-month revealed almost normal direction and distribution of filiform papillae. However, some papillae still suffered signs of destruction. They were conical in shape and long.
The filliform papillae were numerous in number covering the dorsal surface and extend to the lateral borders (fig.5D).

The fungiform papillae showed almost normal appearance and size with well -defined taste buds. Taste pores were obvious on the surface of the fungiform papillae along with some scaling cells at higher magnification.

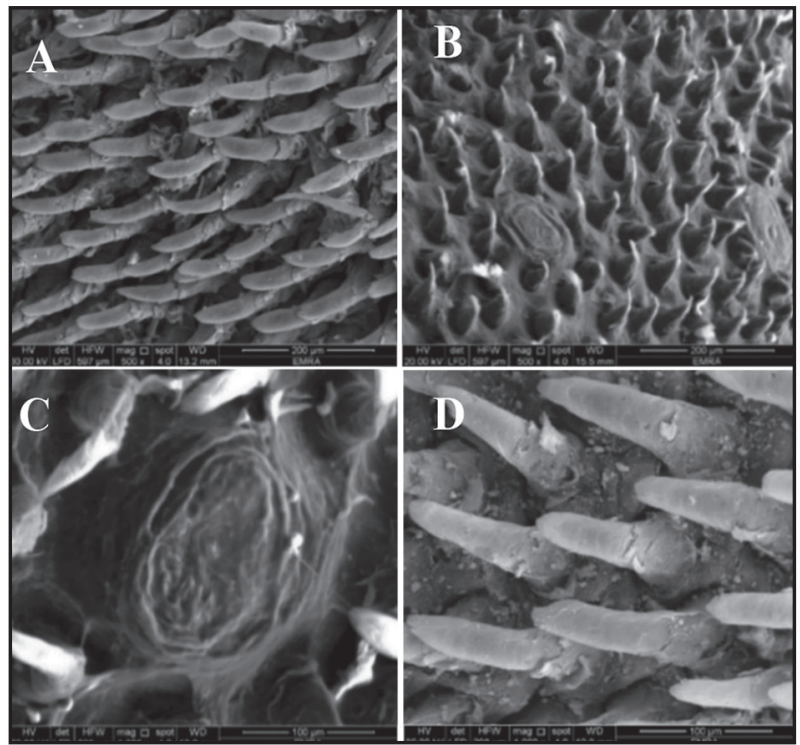

Fig. (5) Scanning electron micrograph showing: A-The dorsal surface of the tongue of group 1 rats showing regular parallel rows of long conical filiform papillae with tapering ends. B-The dorsal surface of the tongue of group 2 rats showing different distribution, extreme thinning and stunting of the filiform papillae. C-The dorsal surface of group 2 rat's tongue showing fungiform papilla with obliterated taste pore. D-The dorsal surface of the tongue of group 3 rats showing well developed filiform papillae with long conical shape (mag. A-X500, B-X500, C-X1000, D-1000). 


\section{DISCUSSION}

In the present investigation the rats received $10 \mathrm{mg} / \mathrm{kg}$ body weight per day of AuNP solution intraperitoneally as a toxic dose coincided with that found by Katsnelson et al ${ }^{17}$.

The intraperitoneal administration was used for studying the toxicity and bio-accumulation of AuNPs by Sadauskas et $\mathbf{a l}^{20,21}$, who investigated effects of nanogold on liver.

The present results reflected atrophic changes in the lingual papillae of tongues of the rats exposed to AuNPs in the form of atrophic filiform papillae with alteration in their normal height and number. They exhibited stunted appearance with total or partial loss of their characteristic conical shape and evident hyperkeratosis. Their epithelial covering showed marked atrophy.

In the current work, taste buds of the fungiform papillae exhibited alteration as many of them showed shrinkage and vacuolization of their cells with peripheral arrangement of the cells leaving an empty center. Others showed complete degeneration of cells.

Similarly, in the liver tissues it was found that the vacuolated swelling of the cytoplasm of the hepatocytes of the AuNPs treated rats might indicate acute and subacute liver injury induced by these AuNPs ${ }^{22}$.

It was found in the current study that the circumvallate papillae also were seriously affected, they lost their normal configuration, appeared atrophic and presented markedly degenerating taste buds, where their remaining cells became surrounded with partially empty spaces with shallowing or partial loss of the furrow surrounding the papillae.

Similar findings were previously reported by Pandey et $\mathbf{a l}^{23}$, who stated that in some hepatocytes of AuNPs treated rats' apoptotic alteration might follow organelles swelling specially mitochondria, endoplasmic reticulum and rupture of lysosomes which might lead to amorphous eosinophilic cytoplasm as an initial sign in the sequence of hepatocytes necrosis before shrinking and dissolution of nuclei. The seen hepatocytes necrosis due to AuNPs exposure might indicate oxidative stress on these cells by glutathione depletion.

The gold nanoparticles were found by Pan et $\mathbf{a}^{24}$, to damage mitochondrial membrane, induce oxidative stress and lead to necrosis. It was also predicted that the gold nanoparticles may produce reactive oxygen species (ROS) affecting membrane lipids, proteins, DNA and endocytic pathway components.

It was showed by Peres et $\mathbf{a l}^{25}$, that oxidative stress is caused by an imbalance between the generation and elimination of ROS. In addition, these formed species may exert harmful effects on cells and organisms. ${ }^{25,26}$ Thus, in conditions of excessive production or if body defenses are compromised, ROS may react with fatty acids, proteins, and DNA, causing damage to these substrates.

In our investigation the size of the gold nanoparticle used is around $30 \mathrm{~nm}$ coincided with that found by Chaves et $\mathbf{a l}^{18}$, who observed that the produced damage increased as the nanoparticle size decreased. Some gold nanoparticles exhibit cytotoxicity and others exhibit non-cytotoxicity depending on the size.

Alteration in the histological structure of the fungiform papillae was also recorded in the current work. The fungiform papillae showed signs of atrophy in their surface epithelium and lamina propria. Taste buds appeared shrunken, partially lost their cells or completely absent.

In our study the underlying lamina propria showed degeneration and dissociation of collagen 
fibers with marked dilatation of blood vessels and their engorgement with blood cells.

Occasional inflammatory cells infiltration was seen in the lamina propria of the tongues of rats treated with gold nanoparticles, similar findings were reported in the portal triads of liver tissue of AuNPs treated rats. The infiltrate cells were mainly lymphocytes and plasma cells. The appearance of inflammatory cells in the affected tissue may suggest that AuNPs could interact with proteins and enzymes of the interstitial tissue interfering with the antioxidant defense mechanism and leading to reactive oxygen species (ROS) generation which in turn may imitate an inflammatory response ${ }^{27}$.

Abdelhalim et $\mathbf{a l}^{28}$, also reported histological alterations in renal tissues of the rats exposed to AuNPs. Sections of AuNPs-treated kidneys developed pyknosis in some epithelium lining cells of the proximal tubules with lesser extent in the distal ones. Pyknotic nuclei exhibited clumping and condensation of the chromatin materials in the periphery of the nuclei together with irregularity of nuclear membranes ${ }^{29}$.

The Haematoxylin and Eosin results of this investigation were confirmed by the immunohistochemical detection of the proliferative cell nuclear antigen (PCNA) that indicates the rate of cell activity of the epithelium of rats treated with AuNPs. The stained sections showed little or no staining with PCNA in the basal cell layer of the tongue epithelium of rats exposed to AuNPs while those of the controls presented strongly positive reaction indicating marked decrease in the rate of turnover and cell renewal of the treated rats.

It has been reported that nuclear targeting of gold nanoparticles in cells cause cytokinesis arrest, leading to the failure of complete cell division and thereby resulting in apoptosis. This showed evidence that nanomaterials localized at the cell nucleus can specifically affect cellular function ${ }^{30}$.

In the present investigation the tongues of the rats which were allowed a recovery period for onemonth after 21 days of intraperitoneal treatment with gold nanoparticles showed improvement in the histological picture of the surface epithelium and lamina propria of the dorsal and ventral surfaces of their tongues.

The filiform papillae showed an apparent increase in their number and height. The fungiform and circumvallate papillae appeared more or less normal without signs of shrinkage or degeneration. Their taste buds got regenerated and appeared more or less normal. The surface epithelium of all types of papillae showed marked increase in thickness and length of their epithelial ridges.

It had been reported that increased AuNP concentrations enhance endocytosis, possibly to compensate for the increased uptake of the nanoparticles and to maintain cell viability. The rate of exocytosis of AuNPs by the cells correlates with the increased $\mathrm{Ca} 2+$ concentration in the extracellular space ${ }^{31}$.

Any cells able to pick up nanoparticles by endocytosis, i.e. pinocytosis or phagocytosis, will either take them up in lysosomes/phagocytomes, or export them out of the cell again. Pinocytosis might be an important factor in the transport of nanoparticles across the blood vessel wall. Recent studies have suggested that transcytosis system across the endothelium is caveollae-mediated process ${ }^{32}$.

In agreement with these findings, the results of the present investigation demonstrated that AuNPs have a degree of toxicity on the tissues but also recovery takes place after a period of time. 


\section{CONCLUSIONS}

Exposure to over dose of AuNPs causes atrophic and degenerative changes that involved the surface epithelium and lamina propria of both the dorsal and ventral surfaces of the tongue. A recovery period of one-month can lead to regeneration and improvement in the histological picture of the surface epithelium and lamina propria.

\section{REFERENCES}

1. Shashirekha G, Jena A, Mohapatra S. Nanotechnology in dentistry: clinical applications, benefits, and hazards. Compend Contin Educ Dent. 2017; 38: 1-4.

2. Farokhzad OC. Nanotechnology for drug delivery: the perfect partnership. Expert Opin Drug Deliv. 2008; 5: 927 929. DOI: 10.1517/17425247.5.9.927.

3. Tao C. Antimicrobial activity and toxicity of gold nanoparticles: research progress, challenges, and prospects. Lett Appl Microbiol. 2018; 67(6): 543-537. DOI: 10.1111/ lam.13082.

4. Singh P, Pandit S, Mokkapati VRS, Garg A, Ravikumar V, Mijakovic I. Gold Nanoparticles in Diagnostics and Therapeutics for Human Cancer. Int J Mol Sci. 2018; 19: 1979. DOI: $10.3390 /$ ijms 19071979.

5. Feng ZV, Gunsolus IL, Qiu TA, Hurley KR, Nyberg LH, Frew H, Johnson KP, Vartanian AM, Jacob LM, Lohse SE, Torelli MD, Hamers RJ, Murphy CJ, Haynes CL. Impacts of gold nanoparticle charge and ligand type on surface binding and toxicity to Gram-negative and Gram-positive bacteria. Chem Sci. 2015; 6:5186-5196. DOI: 10.1039/ c5sc00792e.

6. Cho TJ, MacCuspie RI, Gigault J, Gorham JM, Elliott JT, Hackley VA. Highly stable positively charged dendron-encapsulated gold nanoparticles. Langmuir. 2014; 30: 38833893. DOI.org/10.1021/1a5002013.

7. Schaeublin NM, Braydich-Stolle LK, Schrand AM, Miller JM, Hutchison J, Schlager JJ, Hussain SM. Surface charge of gold nanoparticles mediates mechanism of toxicity. Nanoscale. 2011; 3: 410-420. DOI: 10.1039/c0nr00478b.

8. Gao W, Xu K, Ji L, Tang B. Effect of gold nanoparticles on glutathione depletion-induced hydrogen peroxide gen- eration and apoptosis in HL7702 cells. Toxicol Lett. 2011; 205: 86-95. DOI: 10.1016/j.toxlet.2011.05.1018.

9. Bachand GD, Allen A, Bachand M, Achyuthan KE, Seagrave JC, Brozik SM. Cytotoxicity and inflammation in human alveolar epithelial cells following exposure to occupational levels of gold and silver nanoparticles. J Nanopart Res. 2012; 14: 1212. DOI.org/10.1007/s11051012-1212-y.

10. Sonavane G, Tomoda K, Makino K. Biodistribution of colloidal gold nanoparticles after intravenous administration: effect of particle size. Colloids Surf B Biointerfaces. 2008; 66: 274-280. DOI: 10.1016/j.colsurfb.2008.07.004.

11. Thakor AS, Paulmurugan R, Kempen P, Zavaleta C, Sinclair R, Massoud TF. Oxidative stress mediates the effects of Raman-active gold nanoparticles in human cells. Small. 2011; 7: 126-136. DOI: 10.1002/smll.201001466.

12. Li JJ, Hartono D, Ong CN, Bay BH, Yung LYL. Autophagy and oxidative stress associated with gold nanoparticles. Biomaterials. 2010; 3: 5996-6003. DOI: 10.1016/j.biomaterials.2010.04.014.

13. Tedesco S, Doyle H, Blasco J, Redmond G, Sheehan D. Oxidative stress and toxicity of gold nanoparticles in Mytilus edulis. Aquat Toxicol. 2010; 100:178-186. DOI: 10.1016/j.aquatox.2010.03.001.

14. Moylan JS, Reid MB. Oxidative stress, chronic disease, and muscle wasting. Muscle Nerve. 2007; 35(4): 411-429. DOI: $10.1002 /$ mus.20743.

15. Piryazev AP, Azizova OA, Aseichev AV, Dudnik LB, Sergienko VI. Effect of gold nanoparticles on production of reactive oxygen species by human peripheral blood leukocytes stimulated with opsonized zymosan. Bull Exp Biol Med. 2013; 156: 101-103. DOI: 10.1007/s10517-013-2288-9.

16. Mateo D, Morales P, Ávalos A, Haza AI. Oxidative stress contributes to gold nanoparticle-induced cytotoxicity in human tumor cells. Toxicol Mech Methods. 2014; 24: 161172. DOI: $10.3109 / 15376516.2013 .869783$.

17. Katsnelson BA, Privalova LI, Gurvich VB, Makeyev OH, Shur VY, Beikin YB. Comparative in vivo assessment of some adverse bioeffects of equidimensional gold and silver nanoparticles and the attenuation of nanosilver's effects with a complex of innocuous bioprotectors. Int J Mol Sci. 2013; 14: 2465-2483. DOI: 10.3390/ijms14022449. 
18. Chaves CL, Alvaredo JS, Bayon MM, Bettmer J, Llopis J, Gonzalez CS. Gold nanoparticles: distribution, bioaccumulation and toxicity. In vitro and in vivo studies. Nanomedicine. 2018; 14:1-12. DOI:10.1016/j.nano.2017.08.011.

19. Drury RAB, Wallington EA. Preparation and fixation of tissues. Carleton's Histological Technique. Oxford University Press. 1980; 5: 41-54. DOI: nla.gov.au/nla.cat-vn2864951.

20. Katsnelson BA, Konysheva LK, Privalova LI, Sharapova NY. Quartz dust retention in rat lungs under chronic exposure simulated by a multicompartmental model: Further evidence of the key role of the cytotoxicity of quartz particles. Inhal Toxicol. 1997; 9: 703-715. DOI. org/10.1080/089583797197953.

21. Sadauskas E, Wallin H, Stoltenberg M, Vogel U, Doering P, Larsen A, Danscher G. Kupffer cells are central in the removal of nanoparticles from the organism. Part Fibre Toxicol. 2007; 4: 10. DOI: 10.1186/1743-8977-4-10.

22. Abdelhalim MA, Jarrar BM. Histological alterations in the liver of rats induced by different gold nanoparticle sizes, doses and exposure duration. J Nanobiotechnology. 2012; 10: 5. DOI: 10.1186/1477-3155-10-5.

23. Pandey G, Srivastava DN, Madhuri S. A standard hepatotoxic model produced by paracetamol in rat. Toxicol Int. 2008; 15: 69-70.

24. Pan Y, Neuss S, Leifert A, Fischler M, Wen F, Simon U, Schmid G, Brandau W, Jahnen-Dechent W. Size-dependent cytotoxicity of gold nanoparticles. Small. 2007; 3: 1941-1949. DOI: 10.1002/smll.200700378.
25. Peres W, Tuñón MJ, Collado PS, Herrmann S, Marroni N, González-Gallego J. The flavonoid quercetin ameliorates liver damage in rats with biliary obstruction. J Hepatol. 2000; 33: 742-750. DOI: 10.1016/s0168-8278(00)80305-0.

26. Halliwell B. Free radicals, antioxidants, and human disease: curiosity, cause, or consequence. Lancet. 1994(8924); 344: 721-724. DOI: 10.1016/s0140-6736(94)92211-x.

27. Johar D, Roth JC, Bay GH, Walker JN, Kroczak TJ, Los $\mathrm{M}$. Inflammatory response, reactive oxygen species, programmed (necrotic-like and apoptotic) cell death and cancer. Rocz Akad Med Bialymst. 2004; 49: 31-39.

28. Abdelhalim MA, Jarrar BM. Renal tissue alterations were size-dependent with smaller ones induced more effects and related with time exposure of gold nanoparticles. Lipids Health Dis. 2011; 10: 163. DOI: 10.1186/1476-511X-10-163.

29. Kumar V, Abbas AK, Aster JC. Robbins basic pathology e-book. Curr Opin Environ Sci Health. 2017; 6: 9-10.

30. Kang B, Mackey MA, El-Sayed MA. Nuclear targeting of gold nanoparticles in cancer cells induces DNA damage, causing cytokinesis arrest and apoptosis. J Am Chem Soc. 2010; 132: 1517-1519. DOI: 10.1021/ja9102698.

31. Chen R, Huang G, Ke PC. Calcium-enhanced exocytosis of gold nanoparticles. Appl Phys Lett. 2010; 97(9): 093706. DOI: org/10.1063/1.3486681.

32. Tuma PL, Hubbard AL. Transcytosis: crossing cellular barriers. Physiol Rev. 2003; 83: 871-932. DOI: 10.1152/ physrev.00001.2003. 